\title{
Nematicidal Activity of Leaf Extracts from Lantana camara L. against Meloidogyne incognita (Kofoid and White) Chitwood and its use to Manage Roots Infection of Solanum melongena $\mathrm{L}$.
}

\author{
Faheem Ahmad*, Mohmad Azhar Rather and Mansoor Ahmad Siddiqui
}

Section of Plant Pathology and Plant Nematology; Department of Botany; Aligarh Muslim University; Aligarh202002, UP, India

\begin{abstract}
Various concentrations of aqueous leaf extract of Lantana camara were assessed in vitro conditions against second stage juveniles $\left(\mathrm{J}_{2}\right)$ of Meloidogyne incognita. The standard concentration ' $S$ ' of leaf extract was found to be highly nematostatic, where nematodes were completely paralyzed after $12 \mathrm{~h}$ and after $48 \mathrm{~h}$ of exposure, 96\% of juveniles were killed at same concentration. However, the mortality of juveniles was $75 \%$ in $S / 2$ dilution at 48 h. The degree of effectiveness and dilutions of extract were directly proportional. The percentage of paralyzed juveniles was decreased, when $J_{2}$ transferred in distilled water after $48 \mathrm{~h}$ incubation in standard aqueous leaf extract. Addition of freeze-dried aqueous extract to sterile sandy substrate at $S / 2$ dilution significantly decreased the root-knot infection to susceptible eggplants whereas second stage juveniles $\left(J_{2}\right)$ that penetrated roots of eggplant were able to complete development in sterile sandy substrate without treatment of freeze-dried aqueous extract.
\end{abstract}

Key words: Eggplant, Root-knot nematode, Nematostatic activity

\section{INTRODUCTION}

Meloidogyne spp., root knot nematode is one of the most harmful nematode pests in both tropical and subtropical crop production regions and cause extensive economic damage worldwide (Sikora and Fernandez, 2005). This nematode is an obligate root-parasite of more than 200 plant species including herbaceous and woody-plants of mono and dicotyledons (Hussey, 1985). Among these, M. incognita (Kofoid and White) Chitwood, M. javanica (Treub) Chitwood, M. arenaria (Neal) Chitwood and M. hapla Chitwood are of the major agronomic concern, being responsible in at least
$90 \%$ of all damage caused by these nematodes (Castagnone-Sereno, 2002).

In the more intensively grown crops, synthetic nematicides are one of the primary means of control. However, with continued use, their efficacy can decline and there are concerns of the impact that these chemicals have on the environment. Many compounds have now been withdrawn from the use, needing to develop new, safe and effective options (Zuckerman and Esnard, 1994). There is an increasing interest in discovering the nematostatic compounds from the plants or/plant products (Chitwood, 2002). Antagonistic nematode plants are defined as those

*Author for correspondence: faheem.amu@gmail.com 
which produce substances that inhibit the growth or are lethal to plant parasitic nematodes in plant tissue and soil, and reduce the nematode population density (Sano, 2005). Hypersensitive reaction can occur in the roots due to the recognition of parasite invasion and disruption of tissue, and can lead to the release of nematicidal substances such as alkaloids, terpenes, phenols, and amine acids (Sano et al., 1983; Tando et al., 1989). The nematicidal activity outside the roots has also been demonstrated (Takasugi et al., 1977). Thus, antagonistic plants have mode of action that may either act as a trap that kills the nematodes after invasion of roots, or which act outside the plant body as an exudates. But the mechanism of nematodes suppression by most of the plants is not fully understood. The objective of this study was to determine the in vitro toxicity of leaf extract of Lantana camara $\mathrm{L}$. on the second stage juveniles $\left(\mathrm{J}_{2}\right)$ of $M$. incognita and to determine how such a plant extract could be used to control the pathogenicity of $M$. incognita on Solanum melongena L. cv. 'Navkiran' (eggplant).

\section{MATERIALS AND METHODS}

\section{Source of nematodes}

Second stage juveniles $\left(\mathrm{J}_{2}\right)$ of $M$. incognita were obtained from a pure culture that was previously initiated by egg masses and propagated on eggplant (S. melongena) in the glasshouse. Egg masses were hand picked using sterilized forceps from heavily infected roots. These egg masses were washed in distilled water, placed in 15 mesh sieves ( $8 \mathrm{~cm}$ in diameter) containing crossed layers of tissue paper in Petri-dishes with water just deep enough to contact the egg masses and incubated 28 $\pm 2^{\circ} \mathrm{C}$ to obtain freshly hatched second stage juveniles $\left(\mathrm{J}_{2}\right)$. Only juveniles collected within $48 \mathrm{~h}$ were used.

\section{Preparation and storage of aqueous leaf extract} Fresh green leaves of $L$. camara $(25 \mathrm{~g})$ were thoroughly washed, chopped and after grinding soaked in $75 \mathrm{ml}$ of distilled water for $24 \mathrm{~h}$. After filtering through two folds of muslin cloth, they were filtered through Whatmann No.1 filter paper. The filtrate was centrifuged at $2400 \mathrm{rpm}$ for 10 min and clear supernatant was stored at $4^{\circ} \mathrm{C}$. This was considered as standard solution ' $\mathrm{S}$ ' and other different concentrations were prepared from standard solution with adding requisite amount of sterilized distilled water at the time of experiment.

\section{In vitro experiment}

For studying the juveniles mobile and immobile activity, $100 \mathrm{~J}_{2}$ of $M$. incognita were suspended in $1 \mathrm{ml}$ of different concentration of leaf extract. All concentrations were replicated four times and nematodes were kept in different concentrations at ambient temperature. After 12, 24 and $48 \mathrm{~h}$ incubation, all mobile and immobile second stage juveniles $\left(\mathbf{J}_{2}\right)$ were counted with the aid of inverted microscope at magnification $100 \mathrm{X}$. The ratio of immobile nematodes/number of total nematodes (mobile + immobile) directly expresse the percentage of paralyzed nematodes. In addition, in order to assess the viability of paralyzed $J_{2}$ Meldola Blue Vital Stain was added to Petri plates (Ogiga and Estey, 1974). Nematodes stained black were dead while those remaining unstained were still alive. Immobile unstained nematodes were considered to be paralyzed.

\section{Mobility recovery and root invasion}

One hundred $\mathrm{J}_{2}$ of $M$. incognita were incubated in Petri plates for $48 \mathrm{~h}$ in $1 \mathrm{ml}$ of distilled water (control) or $1 \mathrm{ml}$ of standard concentration of leaf extract of $L$. camara. After treatment with $L$. camara extract, the nematodes were washed four times and resuspended in distilled water. Both mobile and immobile nematodes in both treatments were counted in each Petri plates as described above at 1, 4, 7 and 10 days after $48 \mathrm{~h}$ incubation to determine their ability to recover active mobility. Then to assess their invasion potential, each nematode batch was inoculated onto three- week old seedling of eggplant cv. 'Navkiran' transplanted in plastic pots $(5 \mathrm{~cm}$ in diameter) containing $150 \mathrm{~g}$ sterilized sand and closed with cotton at the bottom. The plants were kept in growth chamber at $25^{\circ} \mathrm{C}$ and irrigated daily with $10 \mathrm{ml}$ distilled water and fed weekly with 10 $\mathrm{ml}$ of nutrient solution (Bertrand et al., 2000). The plants were uprooted 35 days after incubation; their roots were harvested, washed free of soil under distilled water and stained with acid fuchsine (Byrd et al., 1983). Nematodes that had penetrated roots were stained red and were counted by examination of all eggplant roots under a binocular microscope at 20X magnification. The percent invasion potential was estimated from the ratio of stained penetrated nematodes to total 
nematodes in the inocula one hundred fresh mobile $M$. incognita $\mathrm{J}_{2}$, suspended in $2 \mathrm{ml}$ of distilled water, were inoculated onto three week old eggplant seedlings in plastic pots prepared as described above. Prior to eggplant transplantation, the sand substrate was supplemented once with $L$. camara freeze-dried leaf extract at S, S/2, S/10 and DW (distilled water). The plants were grown, irrigated and fed as described above, and were uprooted $1,4,7$ and 10 days after nematodes inoculation. Nematode infestation of roots was estimated as described above.

\section{Statistical analysis}

The data were analyzed by one-way analysis of variance (ANOVA) using SPSS 12.00 software (SPSS Inc., Chicago, IL, USA). Least significant differences (L.S.D) were calculated at $p=0.05$ and Duncan's Multiple Range Test (DMRT) was employed to test for significant differences between the treatments.

\section{RESULTS AND DISCUSSION}

Second stage juveniles $\left(\mathrm{J}_{2}\right)$ of $M$. incognita exhibited the nematostatic reaction in vitro for $L$. camara leaf extract. The standard aqueous solution of leaves which gave up to $96 \%$ immobilization activity when exposed for $48 \mathrm{~h}$ while $\left(\mathrm{J}_{2}\right)$ were immobilized up to $47.25 \%$ when exposed for $12 \mathrm{~h}$ in same aqueous extract. The immobilization rate of juveniles $\left(\mathrm{J}_{2}\right)$ was too low in $\mathrm{S} / 10$ aqueous extract as compared to standard aqueous extract. The immobility of second stage juveniles $\left(\mathrm{J}_{2}\right)$ was more influenced with increasing extract strength of leaves $(S / 10$ to $S)$. The biological effect of aqueous leaf extract of $L$. camara on nematodes resulted in juveniles paralysis and this correlated with extract concentrations (Table1).

In vitro reversibility experiment, second stage juveniles incubated in aqueous leaf extract of $L$. camara remained immobile at 1 day after transfer in distilled water (Fig.1). After then the percentage of immobile individuals significantly decreased when the juveniles were maintained in distilled water and mobility returned to levels comparable to the control after $48 \mathrm{~h}$ incubation. There was also small percentage paralyzed nematodes. After treatment with aqueous extract and washing with distilled water, juveniles $\left(\mathrm{J}_{2}\right)$ having recovered mobility were able to penetrate in eggplant roots at a comparable level to untreated juveniles.

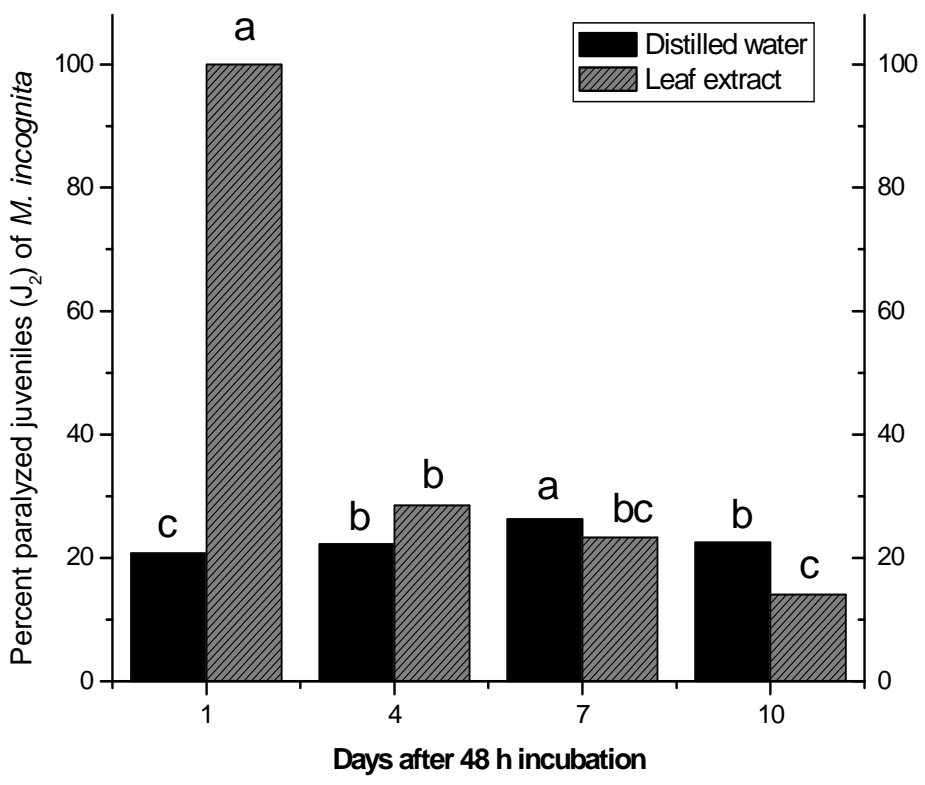

Figure 1 - In vitro reversibility of paralysis of second stage juveniles $\left(\mathrm{J}_{2}\right)$ of $M$. incognita transferred to distilled water after $48 \mathrm{hrs}$ incubation in standard aqueous leaf extract of $L$. camara ( Data with same letters are not significantly different at $p=$ 0.05 according to Duncan's Multiple Range Test). 
Table 1 - In vitro nematostatic effect of leaf extract of $L$. camara on the second stage juveniles $\left(\mathrm{J}_{2}\right)$ of $M$. incognita (\% immobile) after 12, 24 and $48 \mathrm{~h}$ incubation period.

\begin{tabular}{|c|c|c|c|c|c|c|}
\hline \multirow{2}{*}{ Plant } & \multirow{2}{*}{$\begin{array}{l}\text { Incubation } \\
\text { period }(\mathbf{h})\end{array}$} & \multicolumn{4}{|c|}{$\begin{array}{l}\text { Percentage of immobile nematodes in different } \\
\text { aqueous concentrations }\end{array}$} & \multirow{2}{*}{ Regression Equations } \\
\hline & & $\mathbf{S}$ & $\mathrm{S} / 2$ & $\mathrm{~S} / \mathbf{1 0}$ & DW & \\
\hline \multirow{3}{*}{ 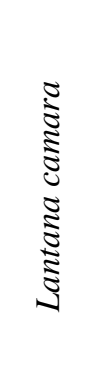 } & 12 & $\begin{array}{c}47.25 \mathrm{~b} \\
(50.7)\end{array}$ & $\begin{array}{c}19.75 \mathrm{~b} \\
(16.9)\end{array}$ & $\begin{array}{l}6.0 \mathrm{~b} \\
(-50.7)\end{array}$ & $\begin{array}{c}0 \\
(50.7)\end{array}$ & $Y=18.3+15.6(X-1.5)$ \\
\hline & 24 & $\begin{array}{l}85.25 \mathrm{a} \\
(92.6)\end{array}$ & $\begin{array}{c}36.25 \mathrm{~b} \\
(30.9)\end{array}$ & $\begin{array}{l}14.5 b \\
(-30.9)\end{array}$ & $\begin{array}{c}0 \\
(-92.6)\end{array}$ & $Y=34.0+27.8(X-1.5)$ \\
\hline & 48 & $\begin{array}{l}96.0 \mathrm{a} \\
(128.2)\end{array}$ & $\begin{array}{l}75.0 \mathrm{a} \\
(42.7)\end{array}$ & $\begin{array}{l}42.7 \mathrm{a} \\
(-42.7)\end{array}$ & $\begin{array}{c}0 \\
(-128.3)\end{array}$ & $Y=53.4+32.0(X-1.5)$ \\
\hline
\end{tabular}

Each mean consists of four replications. Values calculated from regression equations are given in parenthesis. Means in each column followed by the same letters are not significantly different at $p=0.05$ according to Duncan's Multiple Range Test.

The addition of $3 \mathrm{ml}$ freeze-dried extract of different concentration around the roots of eggplants induced a very significantly decrease in nematodes penetration (Table 2). The freeze-dried material of standard aqueous extract of leaves were very effective against root-knot nematodes. Regardless of the extract concentration of leaf added to sand, juveniles $\left(\mathbf{J}_{2}\right)$ that penetrated roots were able to complete development. In control (DW) as well as in S/10 concentration of leaf extract, penetration rates increased at 10 days after inoculation and second stage juveniles were able to mature to fourth stage and achieved their full development into mature female. Nevertheless, aqueous extract of L. camara used as amendment at higher strength significantly decreased the proportion of nematodes that penetrated susceptible eggplant roots. This inhibition in penetration by aqueous extract to improved plant growth compared to infested eggplant.

Table 2 - Invasion of eggplant roots by second stage juveniles $\left(\mathrm{J}_{2}\right)$ of $M$. incognita inoculated in sandy soil supplemented with different aqueous concentrations of leaf extract of $L$. camara.

\begin{tabular}{ccccc}
$\begin{array}{c}\text { Days } \\
\text { after } \\
\text { inoculation }\end{array}$ & $\mathbf{4}$ Nematode invading roots (\% inoculation) \\
\cline { 2 - 5 } & $\mathbf{S}$ & $\mathbf{S} / \mathbf{2}$ & $\mathbf{S} / \mathbf{1 0}$ & $\mathbf{D W}$ \\
\hline 1 & - & $\mathrm{c}$ & $\mathrm{c}$ & $\mathrm{c}$ \\
& & $2.75 \pm 0.479$ & $5.50 \pm 0.646$ & $8.5 \pm 0.646$ \\
4 & - & $\mathrm{c}$ & $\mathrm{c}$ & $\mathrm{c}$ \\
& & $5.50 \pm 0.645$ & $10.0 \pm 0.913$ & $14 \pm 1.472$ \\
7 & - & $\mathrm{b}$ & $\mathrm{b}$ & $\mathrm{b}$ \\
& & $12.50 \pm 1.708$ & $19.75 \pm 0.854$ & $27.0 \pm 1.291$ \\
10 & & $\mathrm{a}$ & $\mathrm{a}$ & $\mathrm{a}$ \\
& & $20.50 \pm 1.190$ & $30.75 \pm 1.377$ & $40.25 \pm 1.376$
\end{tabular}

\footnotetext{
Values are given in Mean \pm S.E. Each mean consists of four replications. Means in each column followed by the same letters are not significantly different at $p=0.05$ according to Duncan's Multiple Range Test.
} 
The suppressive effect of some phytochemical compounds on nematodes population has been well documented in several pathosystem (Chitwood, 2002). The compounds could be developed for use as nematicides themselves, or could serve as model compounds for the development of environmental-friendly synthetic derivates. The nematicidal and nematostatic activities of $L$. camara against root-knot nematodes, Meloidogyne spp., have also been evaluated in vitro and in soil (in vivo) experiments (Ahmad et al., 2010; Qamar et al., 2005). However, in this study, immobile juveniles were described dead nematodes but without testing this. This study on L. camara leaf extract demonstrated paralysis of $\mathrm{J}_{2}$ of $M$. incognita and from the vital staining techniques (Ogiga and Estey, 1974). It was concluded that $L$. camara aqueous leaf extract did not act as strong nematicide on the juveniles were not killed by the plant leaf extract but only paralyzed. Consequently, the biological activity of L. camara leaf extract could be considered to be a nematostatic effect.

A number of wild plants growing throughout the world produce compounds having an immobilizing effect on $M$. incognita. These compounds are likely secondary metabolic products, and while not involved in primary metabolism, contribute to the defense of the plants. Lantana camara also contain pentacyclic triterpenoids described as camaric acid, lantanilic acid and olenolic acids and their nematicidal activities against $\mathrm{J}_{2}$ of $M$. incognita have also been reported (Begum et al., 2008; Qamar et al., 2005; Shaukat and Siddiqui, 2001). The protection of eggplants roots from infection caused by $M$. incognita by the extract of $L$. camara added to substrate could be due to either (i) loss of mobility due to paralysis as revealed here by in vitro experiment, or (ii) disturbed orientation and host findings (linked to disturbance of chemoreception or injuries of sensory organs) disrupting the nematodes co-ordinance in stimuli gradients and affecting the response to root attractants. Such consequences of behavioral disturbance were suggested by Green (1971).

Therefore, these observations on the nematostatic activity of leaf extract of $L$. camara on $M$. incognita clearly indicated another mechanism for the control of root-knot nematodes population by green manure. Usually green manure causes reduction of nematodes by increasing the release of ammonia (Rodriguez-Kabana, 1986) and enhancing antagonists to nematodes (Sikora,
1992). Allelopathic plants at higher concentrations may well produce phytotoxic symptoms. It is therefore, advisable that before $L$. camara is applied under field conditions to suppress the plant parasitic nematodes, optimal concentrations should be determined which could be toxic to nematodes but neither to the plants to be protected nor to any associated beneficial microorganisms such as those possessing bio-control and growth promoting properties. Present data emphasis the significance of protection susceptible eggplant by the addition to substrate of aqueous leaf extract of $L$. camara. The observations that leaf extract of $L$. camara reversibly paralyzed $M$. incognita provided now insight into mechanism by which the green manure reduced the nematodes population (Ahmad et al., 2010). Although the specific components in the leaves of L. camara responsible for this paralysis remain to be determined their identification should assist in the selection and development of specific compounds with enhanced nematode antagonism. The introduction of natural plant products by either cultural practices such as inter-planting or rotation or by industrial production and application of active compounds or its analog would also require detailed information about long term effect on soil population.

\section{CONCLUSIONS}

It was noted that all the concentrations of leaf extract were deleterious to root-knot nematode, $M$. incognita. This finding could be important from the point of view of controlling the root-knot nematode without the use of chemical pesticides in view of environmental pollution likely to cause. The control of $M$. incognita by the leaf extracts used in this study might be probably based on a complex mode of action involving multiple mechanisms. Therefore, future studies are needed to characterize the active compounds in the test plant parts that are nematicidal and possessing complex modes of action.

\section{REFERENCES}

Ahmad, F.; Rather, M.A.; Siddiqui, M.A. (2010), Influence of organic additives on the incidence of root-knot nematode, Meloidogyne javanica in roots of 
tomato plants. Archives of Phytopathology and Plant Protection, 43, 168-173.

Begum, S.; Zehra, S.Q.; Siddiqui, B.S.; Fayyaz, S.; Ramzan, M. (2008), Pentacyclic Triterpenoids from the Aerial Parts of Lantana camara and Their Nematicidal Activity. Chemistry and Biodiversity, 5, 1856-1866.

Bertrand, H.; Nalin, R.; Bally, R.; Cleyet-Marel, J.C. (2000), Isolation and identification of the most efficient plant growth promoting bacteria associated with canola (Brassicus napus). Biology and Fertility of Soils, 33, 151-152.

Byrd, D.W.; Kirkpatrick, T.; Barker, K.R. (1983), An improved technique for clearing and staining plant tissue for detection of nematodes. Journal of Nematology, 15, 142-143.

Castagone-Sereno, P. (2002), Genetic variability in parthenogenetic root-knot nematodes, Meloidogyne spp., and their ability to overcome plant resistance genes. Nematologica, 4, 605-608.

Chitwood, D.J. (2002), Phytochemical based strategies for nematode control. Annual Review of Phytopathology, 40, 221-249.

Green, C.D. (1971), Mating and host finding behavior of plant nematodes. In: Plant Parasitic Nematodes, ed. Zuckerman, B.M., Mai, W.F. and Rohde, R.A. Academic Press, New York, pp. 247-266.

Hussey, R.S. (1985), Host parasite relationships and associated physiological changes. In: An advanced treatise on Meloidogyne, ed. Barker, K.R., Carter, C.C., Sasser, J.N. Raleigh, North Carolina State University Graphics, pp. 143-153.

Ogiga, I.R.; Estey, R.H. (1974), The use of Meldola blue and Nile Blue A., for distinguishing dead from living nematodes. Nematologica, 20, 271-276.

Qamar, F.; Begum, S.; Raza, S.M.; Wahab, A.; Siddiqui, B.S. (2005), Nematicidal natural products from the aerial parts of Lantana camara L. Natural Product Research, 19, 609-613.

Rodriguez-Kabana, R. (1986), Organic and inorganic nitrogen amendments to soil as nematode suppressants. Journal of Nematolology, 18, 129-135.
Sano, Z. (2005), Cultural control of the nematode damage. In: Large encyclopedia of environmental conservation agriculture, ed. Noubunkyo. Noubunkyo, Tokyo, pp. 281-316.

Sano, Z.; Nakasono, T.; Araki, M. (1983), Penetration and development of Meloidogyne incognita in some enemy and host plants. Kyushu Plant Protection Research, 29, 132-136.

Shaukat, S.S.; Siddiqui, I.A. (2001), Lantana camara in the soil changes the fungal community structure and reduces impact of Meloidogyne javanica on Mungbean. Phytopathologia Mediterranea, 40, 245252.

Sikora, R.A. (1992), Management of the antagonistic potential in agricultural ecosystems for the biological control of plant parasitic nematodes. Annual Review of Phytopathology, 30, 245-247.

Sikora, R.A.; Fernandez, E. (2005), Nematode parasites of vegetables. In: Plant Parasitic Nematodes in subtropical and Tropical Agriculture, ed. Luc, M., Sikora, R.A., Bridge, J. CABI Publishing, Wallingford, UK, pp. 319-392.

Takasugi, M.; Toda, H.; Takasugi, Y.; Masamune, N.; Kegasawa, K. (1977), The relation between the structure of asparagusic acid related compounds and their nematicidal activity. Res. Bull Hokkaido National Agricultural Experiment Station, 118, 105111.

Tando, A.S.; Atwal, A.S.; Bajaj, Y.P.S. (1989), In vitro inhibition of root-knot nematode, Meloidogyne incognita by sesame root exudates and its amino acids. Nematologica, 35, 115-124.

Zuckerman, B.M.; Esnard, J. (1994), Biological control of plant nematodes current status and hypothesis. Japanese Journal of Nematology, 24, 1-13.

Received: June 15, 2008; Revised: February 25, 2009; Accepted: October 20, 2009. 